\title{
Antibody response in COVID-19 patients with and without re-positive RT-PCR results during the convalescent phase
}

\author{
Jing Peng ${ }^{1} \cdot$ Zhi-Yong Liu $^{1} \cdot$ Xiao-Juan Yu$^{2} \cdot$ Xiao-Yan Chen ${ }^{1} \cdot$ Kai Zhang ${ }^{1} \cdot$ Yi Liu $^{1} \cdot$ Ying-Ying Su $^{2} \odot \cdot$ Chang-Qing Sun ${ }^{1}$
}

Received: 23 December 2020 / Accepted: 21 April 2021 / Published online: 8 June 2021

(c) The Author(s), under exclusive licence to Springer-Verlag GmbH Austria, part of Springer Nature 2021

\begin{abstract}
Nucleic acid testing and antibody testing data from 143 recovered COVID-19 patients during the convalescent phase were retrospectively analyzed. A total of $23(16.1 \%)$ recovered patients re-tested positive for SARS-CoV-2 RNA by RT-PCR. Three months after symptom onset, $100 \%$ and $99.3 \%$ of the patients remained positive for total and IgG antibodies, and the antibody levels remained high. IgM antibodies declined rapidly, with a median time to seroconversion of 67 (95\% CI: 59, 75 ) days after onset. Approximately $25 \%$ of patients were seronegative for IgA antibodies at three months after onset. There was no statistically significant difference in antibody kinetics between patients with and without re-positive RT-PCR results during the convalescent phase.
\end{abstract}

Coronavirus disease 2019 (COVID-19) is now pandemic globally, spreading rapidly to over 200 countries, with over 117 million confirmed cases and 2.6 million deaths up to March 8, 2021 [1, 2]. After discharge from the hospital, most recovered COVID-19 patients remain negative (non-re-positive) for novel severe acute respiratory syndrome coronavirus 2 (SARS-CoV-2) RNA by RT-PCR, while a proportion of recovered COVID-19 patients test positive again (re-positive) [3-5]. Young and mild-COVID-19 patients seemed to have a higher risk of having re-positive RT-PCR results during the convalescent phase $[3,6]$. The antibody level tends to be similar in the re-positive and non-re-positive groups [3,

Handling Editor: William G Dundon.

Jing Peng, Zhi-Yong Liu, Xiao-Juan Yu contributed equally to this work.

Ying-Ying Su

yingyingsu@xmu.edu.cn

$\triangle$ Chang-Qing Sun

sunchangqing@ssmc-sz.com

1 Shenzhen Sami Medical Center, 1 Jinniu West Road, Pingshan District, Shenzhen, Guangdong Province, China

2 State Key Laboratory of Molecular Vaccinology and Molecular Diagnostics, National Institute of Diagnostics and Vaccine Development in Infectious Diseases, Strait Collaborative Innovation Center of Biomedicine and Pharmaceutics, School of Public Health, Xiamen University, Xiang' an South Road, Xiamen 361102, Fujian, China
6]. However, these studies included only one antibody test per patient and did not adjust for the time of onset, which was significantly correlated with antibody level. It remains unclear whether the dynamics of the antibody response are different in re-positive and non-re-positive patients. This study analyzed the dynamics of total, $\operatorname{IgA}$, IgM, and IgG antibodies in COVID-19 patients during the convalescent phase to understand the kinetics of antibody response in recovered patients.

In Shenzhen, all COVID-19 patients were treated in a designated hospital (the Shenzhen Third People's Hospital). Patients were discharged if they met the following criteria: a) normal body temperature for more than three days, b) significant improvement in respiratory symptoms, c) significant improvement in absorption of acute exudative lesions on lung imaging, and d) negative nucleic acid testing of two consecutive respiratory specimens (at least one day between samplings). After discharge from the designated hospital, the recovered patients were also required to be quarantined in the Shenzhen Sami Medical Center for 14 days of medical observation. Considering the possibility of extended duration of viral shedding in feces [7], nasopharyngeal and anal swabs were collected for SARS-CoV-2 RT-PCR on days 7 and 14 during the 14-day quarantine period. Serum was collected at least one time for antibody testing. If patients remained negative (non-re-positive) by RT-PCR during the 14-quarantine period, they were discharged. If the patient tested positive again by RT-PCR (re-positive), they were re-admitted to 
the designated hospital. After discharge, all patients were also invited to make semi-monthly or monthly follow-up visits for collection of blood samples for antibody testing. All participants provided written informed consent. This study retrospectively reviewed and analyzed the medical records of recovered COVID-19 patients in the Shenzhen Sami Medical Center. A total of 143 recovered COVID19 patients with an exact date of symptom onset available were included in this study. This study was approved by Medical Ethical Committee of Shenzhen Sami Medical Center.

Nasopharyngeal and anal swabs were sent to the Shenzhen Center for Disease Control and Prevention (CDC) for RT-PCR testing as described previously [6]. Briefly, nucleic acids were extracted using a High Pure Viral RNA Kit (Roche, Mannheim, Germany). Nucleic acid amplification and identification were performed using a commercial RT-PCR assay targeting the ORF1ab and N genes of SARS-CoV-2 (Bio-Germ, Shanghai, China). The assay was approved by China's National Medical Products Administration. Total, IgA, IgM, and IgG (all IgG subclasses) antibodies against the receptor-binding domain (RBD) of the SARS-CoV-2 spike protein in the sera of COVID-19 patients were detected using a commercial chemiluminescence microparticle immunoassay (CMIA, Xiamen InnoDx Biotech Co., Ltd., China) as described previously [8]. Briefly, total antibody detection was based on a double-antigen sandwich method. A capture method was applied to detect the IgM antibodies. For the detection of IgG and IgA, an indirect method was used. The test procedure for all assays was performed following the manufacturer's instructions. Antibody levels were expressed as relative binding signals compared to the cutoff value of each assay ( $\mathrm{S} / \mathrm{CO})$. The sensitivity of detection of total, $\mathrm{IgM}, \mathrm{IgG}$, and IgA antibodies was $96.3 \%, 86.3 \%, 99.6 \%$ and $91.9 \%$, respectively. The specificity of detection of total, $\mathrm{IgM}, \mathrm{IgG}$, and $\mathrm{IgA}$ antibodies was $99.3 \%, 99.3 \%$, $99.0 \%$, and $98.6 \%$, respectively (unpublished data for IgG and $\operatorname{Ig} \mathrm{A})[8]$.

Geometric mean titers (GMTs) with $95 \%$ confidence interval were calculated for total, $\operatorname{Ig} \mathrm{A}$, IgM, and IgG antibodies by days post-symptom-onset. Multivariable logbinomial regression models with generalized estimating equations were used to compare the antibody level between the re-positive and non-re-positive groups, adjusted for age and days post-onset. The probability of seropositivity and median time to seronegativity were calculated using the Kaplan-Meier method and compared using the log-rank test. All analyses were performed using SAS software (version 9.4), and a $p$-value less than 0.05 was considered statistically significant.

From March 4 to April 29, 2020, 306 recovered COVID19 patients were under medical observation at the Shenzhen
Sami Medical Center. From among these patients, 143 (46.7\%) with an exact symptom onset date available were included in this study. During the 14-day medical observation period, a total of $23(16.1 \%)$ recovered patients tested positive again by RT-PCR: $14(60.9 \%, 14 / 23)$ on day 7 and $9(39.1 \%)$ on day 14 . As shown in Table 1, the median duration of treatment at the designated hospital was 31 days (IQR: 23-39). The median age (IQR) of the re-positive and non-re-positive patients was $50(34,58)$ and $50(37,61)$, respectively. Sixty-seven patients $(46.9 \%)$ were male. The median follow-up was 45 days (IQR: 40-70, range: 26-96) post-onset for all patients. Patients with re-positive RT-PCR results were followed up longer than those without (72 days vs. 44 days post-onset).

A total of 275 blood samples were collected from 143 patients, with a median of 4 and 1 samples from the re-positive and non-re-positive group, respectively. All recovered patients were seropositive for total antibodies in their first sample taken at the medical center. As shown in Fig. 1, total antibody levels slowly decreased and remained at high S/ $\mathrm{CO}$ values around three months after onset (GMT $=162.5$, 95\%CI: 64.7-408.0). No patient was seronegative at the last sampling time. For IgG antibodies, the levels remained at a plateau from 1 month to 3 months after onset. Only one patient was negative for $\mathrm{IgG}$ antibody at 53 days after onset. IgM antibody levels declined faster than those of other antibodies, with a median time to seroconversion of 67 (95\% CI: 59,75) days after onset. The rate of decline of IgA antibodies was intermediate between those of IgM and IgG. Approximately $25 \%$ of patients were seronegative for IgA

Table 1 Baseline characteristics of patients

\begin{tabular}{|c|c|c|c|}
\hline Variable & Re-positive & Non-re-positive & Total \\
\hline Number & $23^{\mathrm{a}}$ & 120 & 143 \\
\hline Age (median, IQR) & $50(34,58)$ & $50(37,61)$ & $50(37,61)$ \\
\hline \multicolumn{4}{|l|}{ Gender $(\%)$} \\
\hline Male & $7(30.4)$ & $60(50.0)$ & $67(46.9)$ \\
\hline Female & $16(69.6)$ & $60(50.0)$ & $76(53.1)$ \\
\hline \multicolumn{4}{|c|}{ Duration of treatment in the designated hospital } \\
\hline Median (IQR) & $35(27,49)$ & $30(22,39)$ & $31(23,39)$ \\
\hline \multicolumn{4}{|c|}{ No. of sera samples collected } \\
\hline $\begin{array}{l}\text { Of each case, median } \\
\text { (IQR) }\end{array}$ & $4(2,5)$ & $1(1,1)$ & $1(1,3)$ \\
\hline Total & 85 & 190 & 275 \\
\hline \multicolumn{4}{|c|}{$\begin{array}{l}\text { Duration of serological follow-up (days after discharge from the } \\
\text { designated hospital) }\end{array}$} \\
\hline Median (IQR) & $27(21,36)$ & $10(5,14)$ & $13(5,15)$ \\
\hline \multicolumn{4}{|c|}{ Duration of clinical follow-up (days after symptom onset) } \\
\hline Median (IQR) & $72(62,80)$ & $44(39.5,62)$ & $45(40,70)$ \\
\hline Range & 40,91 & 26,96 & 26,96 \\
\hline
\end{tabular}

${ }^{\mathrm{a}} 19(82.6 \%)$ patients tested positive only with nasopharyngeal swabs, $4(17.4 \%)$ only with anal swabs. 

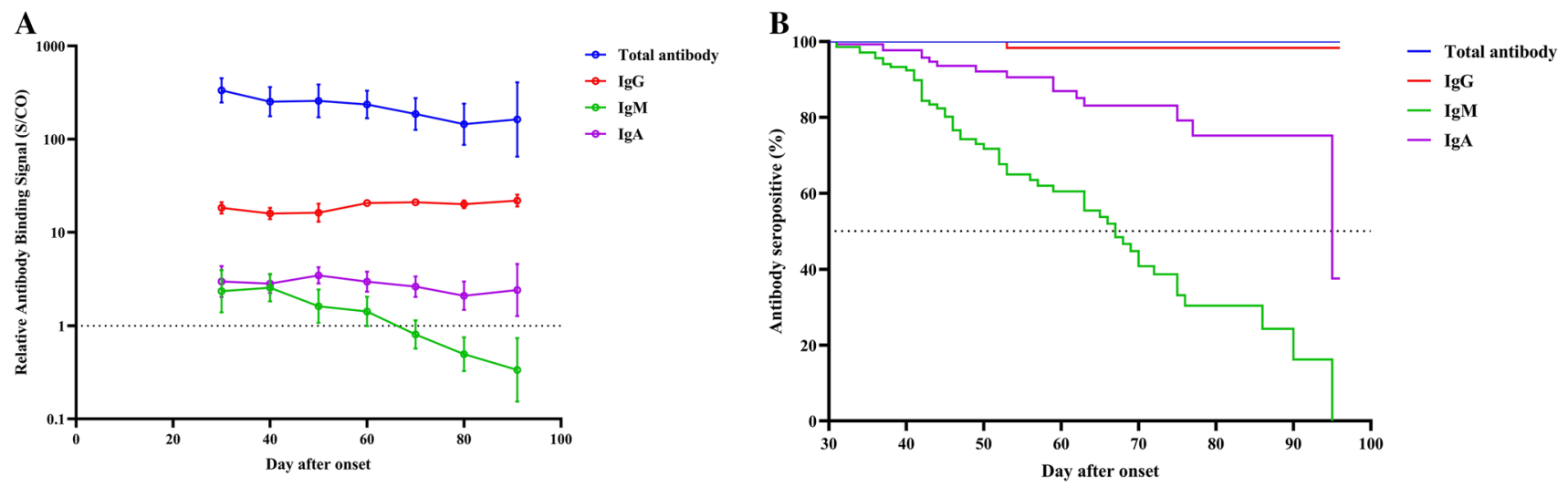

Fig. 1 Antibody kinetics of all COVID-19 patients during the convalescent phases $(n=143)$. A Changes in levels of total, IgG, IgM and IgA antibodies. B Kaplan-Meier estimates of the probability of seropositivity for total, IgG, $\operatorname{IgM}$, and $\operatorname{IgA}$ antibodies

antibodies at three months post-onset. The antibody levels and the seropositivity rate for total, $\operatorname{IgG}, \operatorname{IgM}$, and $\operatorname{Ig} A$ were similar among patients with and without re-positive RT-PCR (all $p$-values higher than 0.05, Fig. 2 and Supplementary Fig. S1).

This study confirmed that IgG antibodies remained stable for three months, consistent with other current studies [9, 10]. The antibody response to SARS-CoV-2 infection may be similar to that of SARS-CoV-1 or other viral infections [11]. The IgM antibody response was transient, and in half of the patients, IgM antibodies were undetectable after about two months. Therefore, similar to other viral infections [12],
IgM antibodies against SARS-CoV-2 may be a marker of acute SARS-CoV-2 infection.

Antibody levels and seropositivity rates for total, IgG, $\operatorname{IgM}$, and $\operatorname{IgA}$ antibodies were similar in patients with and without re-positive RT-PCR results. Studies have shown that the SARS-CoV-2 nucleic acids can be detected in lowerrespiratory-tract specimens and feces for up to 50 days [5, 7]. In addition, the sample quality, sensitivity, and specificity of commercial test kits may result in false-negative results, which to some extent explains why some patients become positive again after a negative result [3]. One study showed that IgG and IgM levels were similar in re-positive
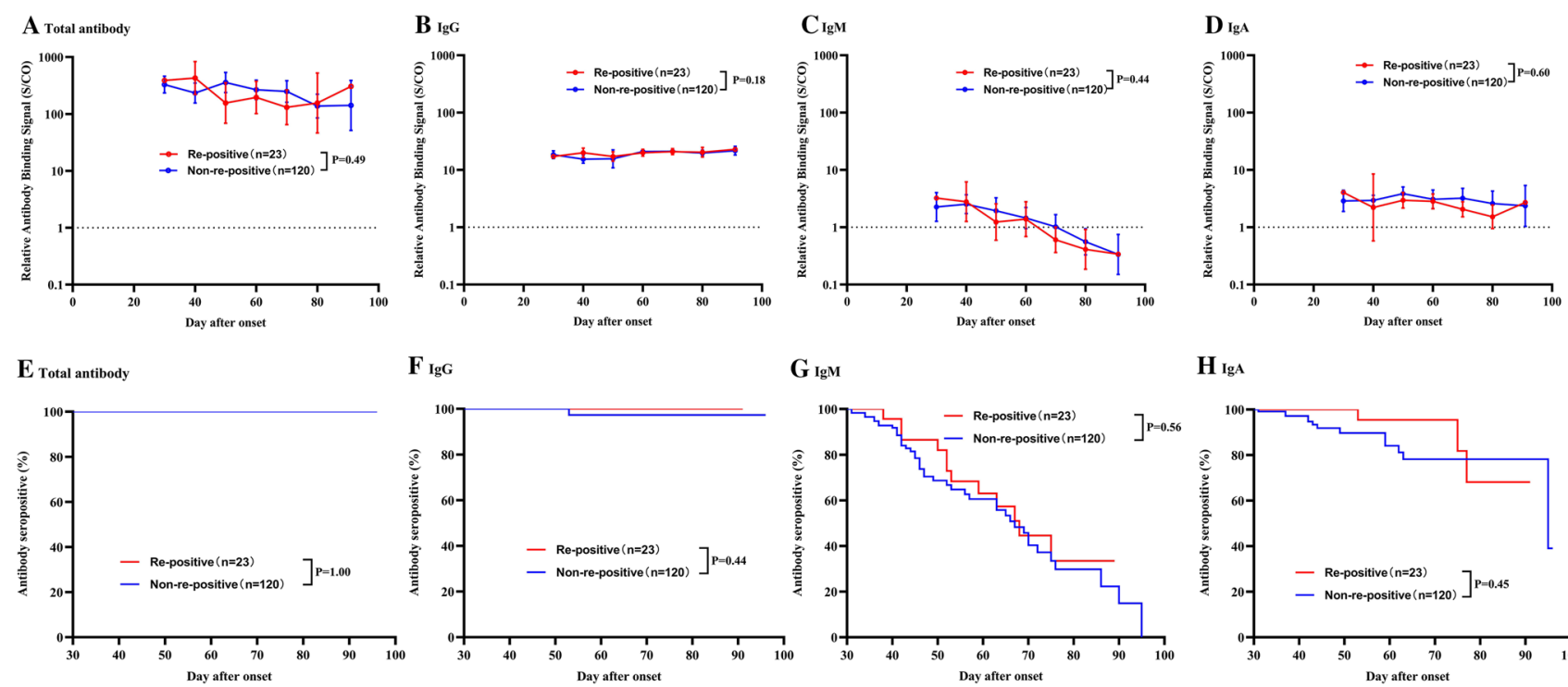

G $\operatorname{Ign}$

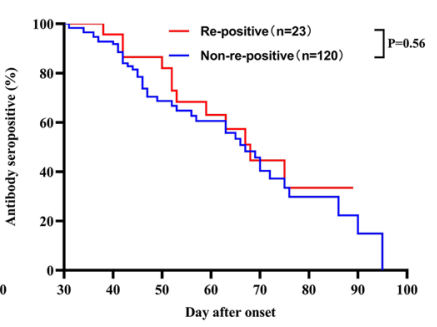

H IgA

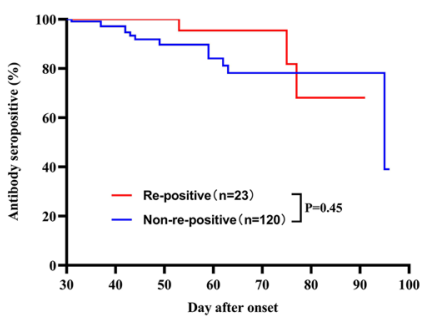

Fig. 2 Comparison of antibody kinetics in COVID-19 patient with and without re-positive RT-PCR results during the convalescent phase. Comparison of antibody levels: A total antibody, B IgG antibody, C IgM antibody, D IgA antibody. $P$-values were estimated using multivariable log-binomial regression models with generalized

estimating equations adjusted for age and days after symptom onset. Kaplan-Meier curves comparing the prevalence of seropositivity: $\mathbf{E}$ total antibody, F IgG antibody, G IgM antibody, H IgA antibody. $P$-values were estimated using the log-rank test 
and non-re-positive patients, which is in agreement with this study [3]. Another preprint study showed that IgG and IgM antibody levels did not correlate with the clinical course of disease and therefore could not be used as a predictor of disease progression.

There are some limitations of this study. The convenience of collection of blood samples resulted in an uneven distribution of sample size over time. Most non-re-positive patients provided only one blood sample during the 14-day quarantine period. They were reluctant to come back to provide blood samples after being discharged. Also, the duration of the follow-up was relatively short.

In conclusion, this study confirmed that high antibody titers for total and $\mathrm{IgG}$ antibodies persisted for three months in recovered COVID-19 patients. IgM antibodies declined rapidly, with a median time to seroconversion of about two months. IgA antibodies declined more slowly than IgM but more rapidly than $\mathrm{IgG}$. Antibody responses were similar between patients with and without re-positive RT-PCR during the convalescent phase.

Supplementary Information The online version contains supplementary material available at https://doi.org/10.1007/s00705-021-05132-9.

Author contributions Conceptualization was performed by JP and C-QS. Investigation was performed by JP, Z-YL, X-YC, KZ and YL. Data curation was performed by Z-YL, X-JY, X-YC, KZ, YL, and C-QS. Methodology was performed by Z-YL, Y-YS and C-QS. Formal analysis was performed by X-JY and Y-YS. Writing of the original draft was performed by JP, Z-YL, X-JY and Y-YS. Reviewing and editing were performed by Y-YS and C-QS. All authors commented on previous versions of the manuscript. All authors read and approved the final manuscript.

Funding This research did not receive any specific grant from funding agencies in the public, commercial, or not-for-profit sectors.

Availability of data and material The data will be available beginning 9 months and ending 36 months following article publication. The data will be shared with investigators whose proposed use of the data has been approved by an independent review committee identified for individual participant data meta-analysis. Proposals should be directed to yingyingsu@xmu.edu.cn or sunchangqing@ssmc-sz.com. To gain access, data requestors will need to sign a data access agreement.

Code availability Software application.

\section{Declarations}

Conflict of interest The authors have declared that no conflict of interest exists.

Ethical approval This study was approved by Medical Ethical Committee of Shenzhen Sami Medical Center.

\section{References}

1. Word Health Organization (2021) Coronavirus disease (COVID19) situation report. https://www.who.int/publications/m/item/ weekly-epidemiological-update---12-january-2021. Accessed 13 Jan 2021

2. Zhu N, Zhang D, Wang W, Li X, Yang B, Song J, Zhao X, Huang B, Shi W, Lu R, Niu P, Zhan F, Ma X, Wang D, Xu W, Wu G, Gao GF, Tan W, I. China Novel Coronavirus and T. Research (2020) A novel coronavirus from patients with pneumonia in China, 2019. N Engl J Med 382(8):727-733. https://doi.org/10.1056/NEJMo a2001017

3. An JH, Liao XJ, Xiao TY, Qian S, Yuan J, Ye HC, Qi FR, Shen CG, Liu Y, Wang LF, Cheng XY, Li N, Cai QX, Wang F, Chen J, Liu YX, Wang YF, Zhang F, Fu Y, Tan XH, Chen J, Liu YX, Wang YF, Zhang F, Fu Y, Tan XH, Liu L, Zhang Z (2020) Clinical characteristics of the recovered COVID-19 patients with redetectable positive RNA test. Ann Transl Med 8(17):1084. https:// doi.org/10.21037/atm-20-5602

4. Lan L, Xu D, Ye GM, Xia C, Wang SK, Li YR, Xu HB (2020) Positive RT-PCR test results in patients recovered from COVID19. JAMA 323(15):1502-1503. https://doi.org/10.1001/jama. 2020.2783

5. Yao XH, He ZC, Li TY, Zhang HR, Wang Y, Mou H, Guo Q, Yu SC, Ding Y, Liu X, Ping YF, Bian XW (2020) Pathological evidence for residual SARS-CoV-2 in pulmonary tissues of a ready-for-discharge patient. Cell Res 30(6):541-543. https://doi. org/10.1038/s41422-020-0318-5

6. Yuan B, Liu HQ, Yang ZR, Chen YX, Liu ZY, Zhang K, Wang C, Li WX, An YW, Wang JC, Song S (2020) Recurrence of positive SARS-CoV-2 viral RNA in recovered COVID-19 patients during medical isolation observation. Sci Rep 10(1):11887. https://doi. org/10.1038/s41598-020-68782-w

7. Wu Y, Guo C, Tang L, Hong Z, Zhou J, Dong X, Yin H, Xiao Q, Tang Y, Qu X, Kuang L, Fang X, Mishra N, Lu J, Shan H, Jiang G, Huang X (2020) Prolonged presence of SARS-CoV-2 viral RNA in faecal samples. Lancet Gastroenterol Hepatol 5(5):434435. https://doi.org/10.1016/s2468-1253(20)30083-2

8. Lou B, Li TD, Zheng SF, Su YY, Li ZY, Liu W, Yu F, Ge SX, Zou QD, Yuan Q, Lin S, Hong CM, Yao XY, Zhang XJ, Wu DH, Zhou GL, Hou WH, Li TT, Zhang YL, Zhang SY, Fan J, Zhang J, Xia NS, Chen Y (2020) Serology characteristics of SARS-CoV-2 infection after exposure and post-symptom onset. Eur Respir J. https://doi.org/10.1183/13993003.00763-2020

9. Gudbjartsson DF, Norddahl GL, Melsted P, Gunnarsdottir K, Holm H, Eythorsson E, Arnthorsson AO, Helgason D, Bjarnadottir K, Ingvarsson RF, Thorsteinsdottir B, Kristjansdottir S, Birgisdottir K, Kristinsdottir AM, Sigurdsson MI, Arnadottir GA, Ivarsdottir EV, Andresdottir M, Jonsson F, Agustsdottir AB, Berglund J, Eiriksdottir B, Fridriksdottir R, Gardarsdottir EE, Gottfredsson M, Gretarsdottir OS, Gudmundsdottir S, Gudmundsson KR, Gunnarsdottir TR, Gylfason A, Helgason A, Jensson BO, Jonasdottir A, Jonsson H, Kristjansson T, Kristinsson KG, Magnusdottir DN, Magnusson OT, Olafsdottir LB, Rognvaldsson S, le Roux L, Sigmundsdottir G, Sigurdsson A, Sveinbjornsson G, Sveinsdottir KE, Sveinsdottir M, Thorarensen EA, Thorbjornsson B, Thordardottir M, Saemundsdottir J, Kristjansson SH, Josefsdottir KS, Masson G, Georgsson G, Kristjansson M, Moller A, Palsson R, Gudnason T, Thorsteinsdottir U, Jonsdottir I, Sulem P, Stefansson K (2020) Humoral immune response to SARS-CoV-2 in Iceland. N Engl J Med 383(18):1724-1734. https://doi.org/10.1056/NEJMoa2026 116

10. Seow J, Graham C, Merrick B, Acors S, Steel KJA, Hemmings O, O’Bryne A, Kouphou N, Pickering S, Galao R, Betancor G, Wilson HD, Signell AW, Winstone H, Kerridge C, Temperton N, 
Snell L, Bisnauthsing K, Moore A, Green A, Martinez L, Stokes B, Honey J, Izquierdo-Barras A, Arbane G, Patel A, L. OConnell, G. O Hara, E. MacMahon, S. Douthwaite, G. Nebbia, R. Batra, R. Martinez-Nunez, J. D. Edgeworth, S. J. D. Neil, M. H. Malim and K. Doores, (2020) Longitudinal observation and decline of neutralizing antibody responses in the three months following SARS-CoV-2 infection in humans. Nat Microbiol 5:1598-1607. https://doi.org/10.1038/s41564-020-00813-8

11. Alter G, Seder R (2020) The power of antibody-based surveillance. N Engl J Med 383(18):1782-1784. https://doi.org/10.1056/ NEJMe2028079
12. Ponde RAA (2017) The serological markers of acute infection with hepatitis A, B, C, D, E and G viruses revisited. Arch Virol 162(12):3587-3602. https://doi.org/10.1007/s00705-017-3538-3

Publisher's Note Springer Nature remains neutral with regard to jurisdictional claims in published maps and institutional affiliations. 